\title{
Poly(ether-carbonate)s from Diphenolates, Cyclic Carbonates, and Dihalo Compounds
}

\author{
Gabriel RoKICKI, Jerzy PAWLICKI, and Witold KURAN \\ Faculty of Chemistry, Technical University (Politechnika), \\ 00-662 Warsaw, Koszykowa 75, Poland
}

(Received June 13, 1984)

\begin{abstract}
Reactions of dipotassium diphenolates with cyclic carbonates and $\alpha, \omega$-dihalo compounds in the presence of 18 -crown-6 ether were studied. Poly(ether-carbonate)s with various contents of carbonate linkage or polyethers were formed in these reactions depending on the kind of diphenolate and dihalo compound and the reaction temperature. The mechanism of carbonate linkage formation involving 1,3-dioxolan-2-one ring opening was discussed in terms of results of studies on the model reaction between 2-(1-phenoxy)propyl potassium carbonate and $\alpha, \alpha^{\prime}$ dibromo-p-xylene.
\end{abstract}

KEY WORDS Dipotassium Diphenolate / Cyclic Carbonate / $\alpha, \omega$-Dihalo

Compound / Crown Ether / Poly(ether-carbonate) / Polyether /

Although the application of carbon dioxide as a monomer for polymer syntheses has received much attention in recent years, rather convenient reactants for synthesis of linear polycarbonates seem to be cyclic alkylene carbonates. The latter compounds are easily available by addition of carbon dioxide to oxiranes. ${ }^{1}$

As far as the present authors know cyclic carbonates have been used for synthesis of polycarbonates by transesterification reaction with aliphatic and cycloaliphatic diols. ${ }^{2}$ Ethylene and propylene carbonates were also tried to be polymerized and the products appeared to contain carbonate as well as ether linkages. ${ }^{3}$

This paper is concerned with a new route for insertion of carbonate units into linear polymer chains involving the reaction system containing dipotassium diphenolates, cyclic alkylene carbonates and $\alpha, \omega$-dihalo compounds. The polymer produced in this system was expected to contain both the carbonate and ether linkages, formed due to the dioxolanone ring opening by the phenolate anion attack on the ring.
It is worthwhile to notice that the reaction of dipotassium diphenolate with carbon dioxide and $\alpha, \omega$-dihalo compound was reported previously ${ }^{4}$ to produce polymers containing carbonate linkages besides ether ones. The latter linkages, however, were formed by the side reaction of the dipotassium diphenolate with $\alpha, \omega$-dihalo compound omitting interaction with $\mathrm{CO}_{2}$.

\section{EXPERIMENTAL}

\section{Materials}

$\alpha, \alpha^{\prime}$-Dibromo- $p$-xylene was obtained from the reaction of $p$-xylene- $\alpha, \alpha^{\prime}$-diol with hydrogen bromide and was purified by crystallization from carbon tetrachloride. ${ }^{5} 4,4^{\prime}$-Bis(bromomethyl)biphenyl was obtained from the reaction of biphenyl with paraformaldehyde in the presence of gaseous hydrogen bromide. ${ }^{6}$ $\alpha, \alpha^{\prime}$-Dichloro- $p$-xylene was obtained from the reaction of $p$-xylene with sulfuryl chloride carried out in the presence of benzoyl peroxide; the product was crystallized from chloroform. $^{7}$ 1,3-Dioxolan-2-one (ethylene car- 
bonate), 4-methyl-1,3-dioxolan-2-one (propylene carbonate), 4-phenyl-1,3-dioxolan-2-one, 4-allyloxymethyl-1,3-dioxolan-2-one were obtained from addition of carbon dioxide to respective oxirane according to the method reported elsewhere. ${ }^{1}$ Solvents were purified according to commonly known methods. 18Crown-6 ether $(1,4,7,10,13,16$-hexaoxacyclooctadecane) was obtained according to the method described in the literature. ${ }^{8}$ Dipotassium 4,4'-isopropylidenediphenolate was obtained according to the following procedure. Under a nitrogen atmosphere $5.71 \mathrm{~g}(25 \mathrm{mmol})$ of $4,4^{\prime}$-isopropylidenediphenol, $50 \mathrm{~cm}^{3}$ of DMSO and $50 \mathrm{~cm}^{3}$ of chlorobenzene were placed into a $200 \mathrm{~cm}^{3}$ flask, equipped with a stirrer, thermometer, dropping funnel and a condenser. The system was heated under nitrogen up to $70^{\circ} \mathrm{C}$ with intensive stirring and the stoichiometric amount of the concentrated, aqueous solution of $\mathrm{KOH}(6.83 \mathrm{~g}$ of $41.0 \%)$ was added. Water from the system was removed by azeotropic distillation with chlorobenzene. Dipotassium 1,4-cyclohexanediolate was obtained from the reaction of 1,4-cyclohexanediol with potassium in THF. ${ }^{9}$

\section{Polymer Synthesis}

In a $50 \mathrm{~cm}^{3}$ glass reaction flask, equipped with a stirrer $5 \mathrm{mmol}$ of dipotassium diphenolate or diolate, $15 \mathrm{~cm}^{3}$ of solvent, adequate amount of cyclic carbonate and 18-crown- 6 ether were placed under nitrogen. The flask content was heated for $15-60 \mathrm{~min}$ then 5 mmol of dihalo compound was added and heated at $80-110^{\circ} \mathrm{C}$ for $5-6 \mathrm{~h}$. The postreaction mixture was filtered to remove potassium halide and after evaporation in vacuo of the part of DMSO or other solvent the isolated product was washed with water and diethyl ether and dried at room temperature in vacuo.

In the case of reaction carried out under carbon dioxide pressure a $50 \mathrm{~cm}^{3}$ stainless steel autoclave was used. Into the autoclave $1.52 \mathrm{~g}$ $(5 \mathrm{mmol})$ of dipotassium 4,4 '-isopropylidenediphenolate, $0.02 \mathrm{~g}(0.7 \mathrm{mmol})$ of 18 -crown-6 ether, $10 \mathrm{~cm}^{3}$ of solvent and appropriate amount of cyclic carbonate were added under nitrogen. Dibromo compound ( $5 \mathrm{mmol}$ ) was placed in a sealed glass ampoule and then introduced to the autoclave. Gaseous carbon dioxide was introduced to the system under a pressure of $30 \mathrm{~atm}$ and the autoclave was heated at the required temperature. After 15$60 \mathrm{~min}$ the ampoule was broken and the reaction was carried out for another 4-6h. After completion of the reaction, $\mathrm{CO}_{2}$ was released from the autoclave and from that moment the procedure was as in the method without $\mathrm{CO}_{2}$ pressure.

The Model Reaction of 2-(1-Phenoxy)propyl Potassium Carbonate with $\alpha, \alpha^{\prime}$-Dibromo-pxylene

In a $50 \mathrm{~cm}^{3}$ pressure autoclave $1.51 \mathrm{~g}(10$ $\mathrm{mmol}$ ) of potassium 2-(1-phenoxy)propanolate obtained analogously, as described elsewhere ${ }^{9}$ was placed under nitrogen. Then, $0.04 \mathrm{~g}$ (1.4 mmol) of 18-crown- 6 ether, $10 \mathrm{~cm}^{3}$ of THF and $1.32 \mathrm{~g}(5 \mathrm{mmol})$ of $\alpha, \alpha^{\prime}$-dibromo- $p$-xylene (placed in sealed glass ampoule) were added. Gaseous carbon dioxide was introduced to the system under a pressure of $30 \mathrm{~atm}$ and autoclave was heated at $100^{\circ} \mathrm{C}$ for $20 \mathrm{~min}$. Then the ampoule was broken and the reaction was carried out for additional $5 \mathrm{~h}$. After the reaction completion the autoclave was cooled, $\mathrm{CO}_{2}$ was released, precipitate of $\mathrm{KBr}$ was filtered off and THF was distilled off in vacuo.

\section{Product Analysis}

IR spectra were recorded on a Perkin-Elmer 521 spectrophotometer. ${ }^{1} \mathrm{H}$ NMR spectra were recorded on a $100 \mathrm{MHz}$ JEOL NMR spectrometer using TMS as an internal standard. Elemental analysis was carried out by a Perkin-Elmer 240 apparatus.

\section{RESULTS AND DISCUSSION}

The product obtained from the reaction of dipotassium 4,4'-isopropylidenediphenolate, 


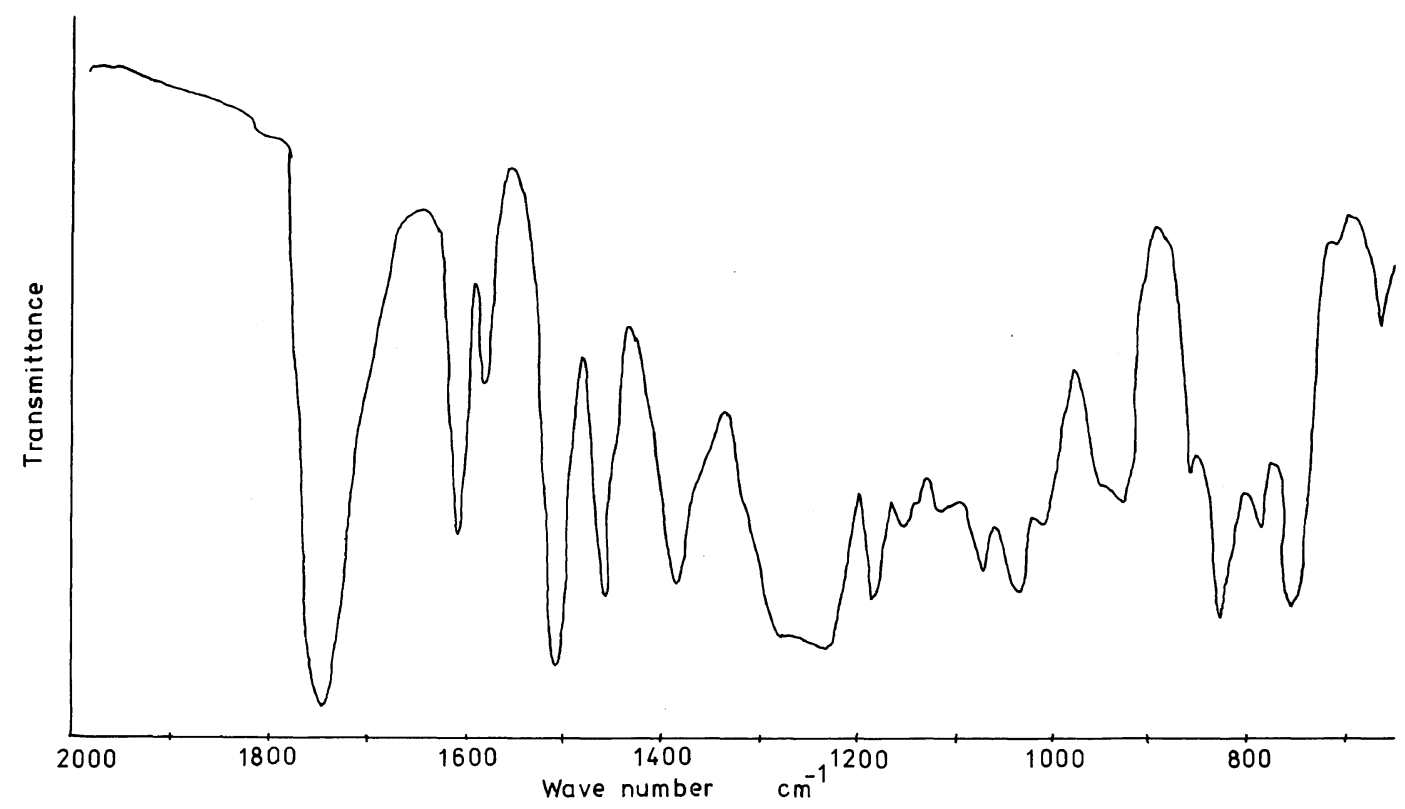

Figure 1. IR spectrum of the product obtained from the reaction of dipotassium 4,4'-isopropylidenediphenolate, 4-methyl-1,3-dioxolan-2-one and $\alpha, \alpha^{\prime}$-dibromo- $p$-xylene (Table I, No. 5).
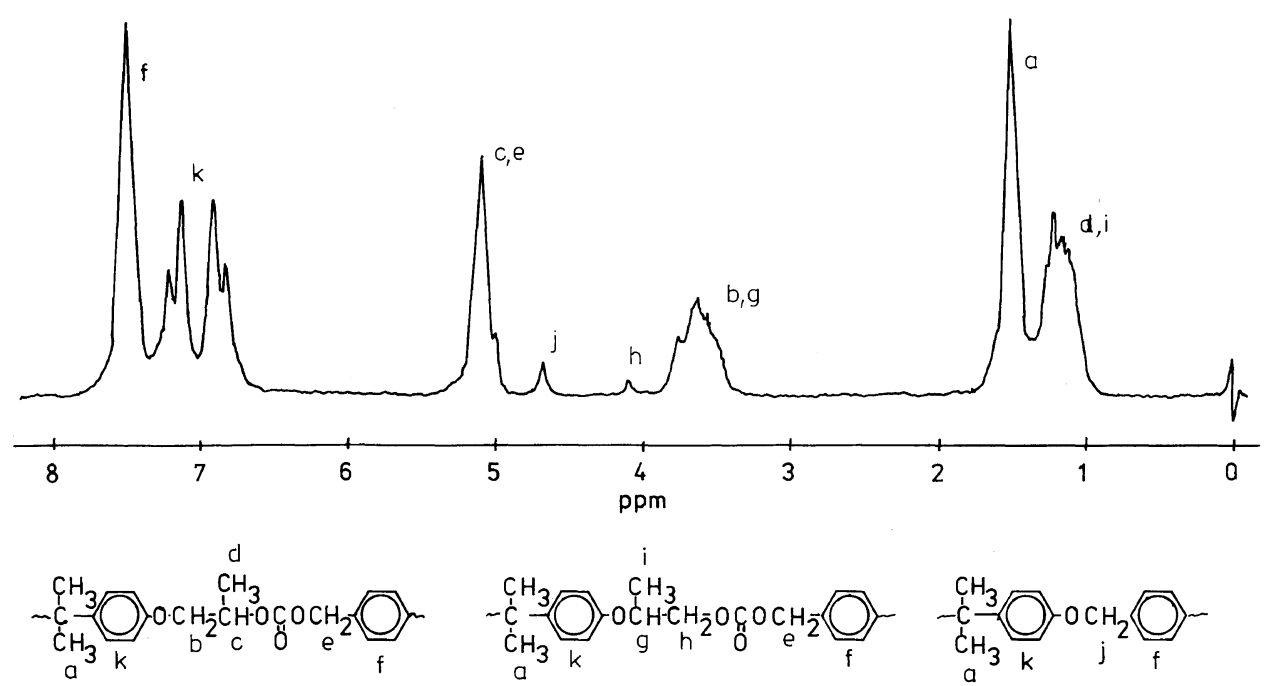

Figure 2. ${ }^{1} \mathrm{H}$ NMR spectrum of the product obtained from the reaction of dipotassium 4,4'-isopropylidenediphenolate, 4-methyl-1,3-dioxolan-2-one and $\alpha, \alpha^{\prime}$-dibromo- $p$-xylene (Table I, No. 5).

4-methyl-1,3-dioxolan-2-one, and $\alpha, \alpha^{\prime}$-dibromo- $p$-xylene in the presence of 18-crown-6 ether were pale-yellow colored solids, soluble in polar solvents and insoluble in water. IR and ${ }^{1} \mathrm{H}$ NMR spectra of representative sam- ples of the products obtained are shown in Figures 1 and 2. In the IR spectrum, strong absorption bands at 1740-1750, 1260-1275, $1100-1150 \mathrm{~cm}^{-1}$, corresponding to the stretching vibration of carbonyl groups, $\mathrm{C}-\mathrm{O}$ 
bonds of linear carbonate and ether bonds, kage $(\delta=4.1 \mathrm{ppm})$, methylene and methine respectively, were observed. In the ${ }^{1} \mathrm{H}$ NMR protons neighboring with ether linkage spectrum, the following signals were present: $(\delta=3.6 \mathrm{ppm}), \quad$ isopropylidene protons aromatic protons $(\delta=7.0$ and $7.5 \mathrm{ppm})$, me- $(\delta=1.4 \mathrm{ppm})$ and methyl protons $(\delta=1.1-$ thine and benzyl methylene protons neigh- $1.2 \mathrm{ppm})$.

boring with the carbonate linkage $(\delta=5.1$ ppm), benzyl methylene protons neighboring with the ether linkage ( $\delta=4.7 \mathrm{ppm})$, methylene protons neighboring with the carbonate lin-

On the basis of these results, the following reaction scheme could be considered as possible reaction route to form poly(ether-carbonate)s.

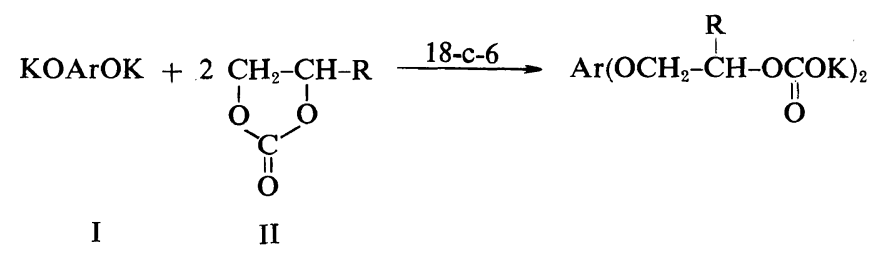

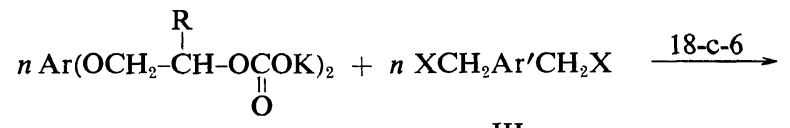

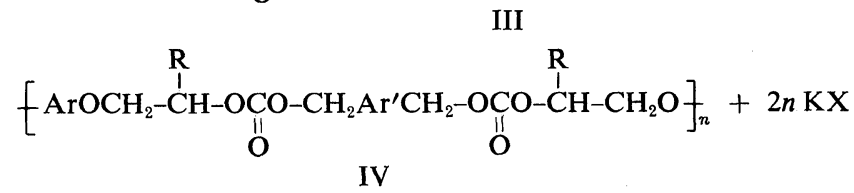<smiles>Cc1ccc(C(C)(C)c2ccc(C#[W])cc2)cc1</smiles>

$\mathrm{R}=\mathrm{H}, \mathrm{CH}_{3}, \mathrm{C}_{6} \mathrm{H}_{5}, \mathrm{CH}_{2}=\mathrm{CH}-\mathrm{CH}_{2} \mathrm{OCH}_{2}$<smiles>Cc1ccc(-c2ccc([Hg]c3ccc([W]=[Al])cc3)cc2)cc1</smiles>

$\mathrm{X}=\mathrm{Br}, \mathrm{Cl}$

Dipotassium diphenolate I reacts with cyclic carbonate II leading to 1,3-dioxolan-2-one ring opening product according to eq 1 . The product formed undergoes then reaction with the dihalo compound III yielding poly(ethercarbonate), according to eq 2 . The presence of the signal of benzyl methylene protons $(\delta=4.7 \mathrm{ppm})$ in the ${ }^{1} \mathrm{H}$ NMR spectrum, however, indicates the polymer chain growth not involving the cyclic carbonate contribution in $100 \%$. Yields and some characteristic data for the poly(ether-carbonate)s formed in the reaction of I, II, and III are presented in Table I.
The halogen content in these products indicates their rather low molecular weight $(n=5-8)$.

The carbonate linkages content in poly(ether-carbonate)s was found to be strongly dependent on the reaction temperature. At temperature in the range of $100-120^{\circ} \mathrm{C}$ the reaction with a participation of cyclic carbonate predominates due to the facile attack of phenolate anion onto 1,3-dioxolan-2-one ring which results in the relatively high content of carbonate linkages in the product (Table I, No. 4 6). Decreasing the reaction tempera- 
Table I. Reaction of dipotassium 4,4'-isopropylidenediphenolate, 4-methyl-1,3-dioxolan-2-one, and $\alpha, \alpha^{\prime}$-dihalo- $p$-xylene

\begin{tabular}{|c|c|c|c|c|c|c|c|c|c|c|c|}
\hline \multirow{3}{*}{$\begin{array}{c}\text { Run } \\
\text { no. }\end{array}$} & \multirow[b]{3}{*}{$\mathrm{X}$} & \multirow{3}{*}{$\begin{array}{c}\begin{array}{c}\text { Dihalo } \\
\text { compound }\end{array} \\
\mathrm{g}(\mathrm{mmol})\end{array}$} & \multirow{3}{*}{$\begin{array}{c}\begin{array}{l}\text { Propylene } \\
\text { carbonate }\end{array} \\
\mathrm{g}(\mathrm{mmol})\end{array}$} & \multirow{3}{*}{ Solvent } & \multirow{3}{*}{$\frac{\text { Temp }}{{ }^{\circ} \mathrm{C}}$} & \multicolumn{2}{|c|}{ Reaction time } & \multirow{2}{*}{$\begin{array}{l}\text { Product } \\
\text { yield }\end{array}$} & \multirow{2}{*}{$X_{\mathrm{c}}^{\mathrm{a}}$} & \multirow{2}{*}{$\operatorname{Br}(\mathrm{Cl})^{\mathbf{b}}$} & \multirow{2}{*}{$\eta_{\mathrm{sp}}{ }^{\mathrm{c}}$} \\
\hline & & & & & & J ston & U cton & & & & \\
\hline & & & & & & $\min$ & & $\mathrm{g}$ & $\%$ & $\%$ & $\mathrm{dlg}^{-1}$ \\
\hline 1 & $\mathrm{Br}$ & $1.32(5)$ & $1.12(11)$ & DOX & 60 & 60 & 5 & 1.41 & 0 & 10.1 & 0.09 \\
\hline 2 & $\mathrm{Br}$ & $1.32(5)$ & $6.00(60)$ & - & 70 & 60 & 6 & 1.32 & 0 & 7.6 & 0.12 \\
\hline 3 & $\mathrm{Br}$ & $1.32(5)$ & $1.12(11)$ & DMSO & 90 & 60 & 4 & 1.50 & 43 & 5.3 & - \\
\hline 4 & $\mathrm{Br}$ & $1.32(5)$ & $1.12(11)$ & DMSO & 100 & 30 & 6 & 1.52 & 73 & 5.0 & - \\
\hline 5 & $\mathrm{Br}$ & $1.32(5)$ & $1.12(11)$ & DMSO & 110 & 60 & 5 & 1.60 & 80 & 6.8 & 0.10 \\
\hline 6 & $\mathrm{Br}$ & $1.32(5)$ & $1.12(11)$ & DMSO & 120 & 60 & 6 & 1.48 & 78 & - & - \\
\hline 7 & $\mathrm{Br}$ & $1.32(5)$ & $6.00(60)$ & - & 120 & 60 & 5 & 0.54 & $5^{d}$ & - & - \\
\hline 8 & $\mathrm{Br}$ & $1.32(5)$ & $6.00(60)$ & DMSO & 120 & - & 6 & 0.81 & 5 & - & - \\
\hline 9 & $\mathrm{Cl}$ & $1.25(5)$ & $6.00(60)$ & DMSO & 120 & - & 6 & 1.10 & 15 & 6.2 & - \\
\hline 10 & $\mathrm{Br}$ & $1.32(5)$ & $1.12(11)$ & DMSO & 170 & 60 & 5 & 0.83 & 0 & 5.2 & - \\
\hline 11 & $\mathrm{Br}$ & $1.32(5)$ & $1.12(11)$ & DMSO & 160 & 60 & 5 & 0.90 & $20^{\mathrm{e}}$ & 6.8 & 0.11 \\
\hline
\end{tabular}

${ }^{\mathrm{a}} X_{\mathrm{c}}$, mole fraction of carbonate linkage calculated from: $X_{\mathrm{c}}=1-(3 / 2) a$, where $a$, the intensity ratio of methylene benzyl protons signals neighbouring with ether linkage $(\delta=4.7 \mathrm{ppm})$ to isopropylidene protons signals $(\delta=$ $1.5 \mathrm{ppm})$ in ${ }^{1} \mathrm{H}$ NMR spectrum.

b The halogen content in the product in $\mathrm{wt} \%$.

c The specific viscosity of a $2 \%$ solution in DMSO at $25^{\circ} \mathrm{C}$.

d Dipotassium 4,4'-isopropylidenediphenolate contained small amount of free hydroxyl groups.

e The reaction was carried out under a pressure of $30 \mathrm{~atm}$ of $\mathrm{CO}_{2}$.

ture causes the formation of the polymer with enhanced ether linkages content and at temperature of $70^{\circ} \mathrm{C}$ and lower only polyether was obtained (Table I, No. 1-2). In the latter reaction no evolution of carbon dioxide was observed which indicates the cyclic carbonate is not susceptible to phenolate anion attack at relatively low temperature. It is interesting to notice that the reaction of I, II, and III run at $110^{\circ} \mathrm{C}$ with the reactants mixed simultaneously gave polymer with a high content of ether linkages (Table I, No. 8). Even for considerable excess of cyclic carbonate in the above system the rate of diphenolate reaction with $\alpha, \alpha^{\prime}$-dibromo- $p$-xylene is much higher than with 1,3-dioxolan-2-one ring. Replacement of the dibromo compound with less reactive $\alpha, \alpha^{\prime}-$ dichloro- $p$-xylene resulted in enhancement of carbonate linkages content in the product obtained (Table I, No. 9). Polyether as the only product has* been found to be formed when dipotassium 4,4'-sulfonyldiphenolate instead of the salt of less acidic diphenol (4,4'-isopropylidenediphenol) was used for the reaction in the system studied, even at temperature higher than $110^{\circ} \mathrm{C}$ (Table II, No. 4) (eq 3).<smiles>CC(=O)Oc1ccc(S(=O)(=O)c2ccc(Oc3ccc(OCOC(=O)OC(C)C)cc3)cc2)cc1</smiles><smiles></smiles> 
It was found in the course of further studies that the formation of poly(ether-carbonate) depends also on the purity of dipotassium salt of diphenol. The presence of free hydroxyl group in the salt causes the decarboxylation side reaction (eq 4) and polyether is formed as the main product (Table I, No. 7).

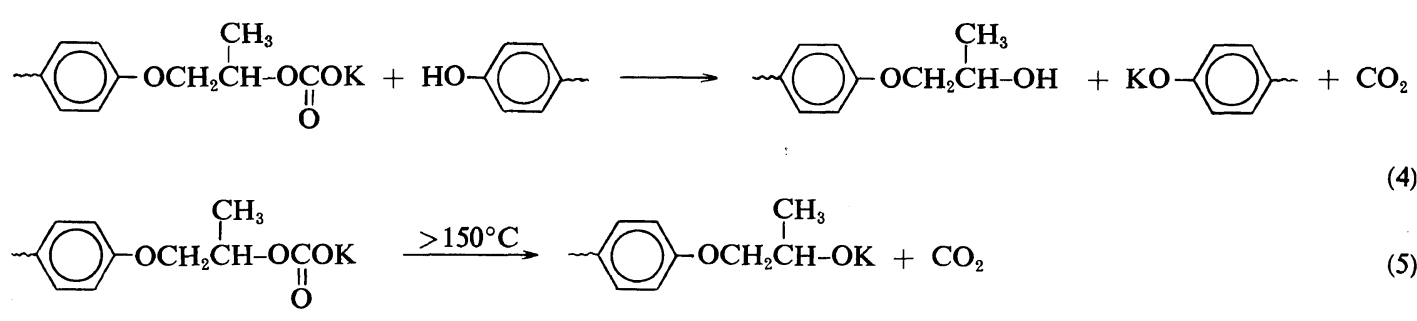<smiles>CC(COc1ccc(F)cc1)OC(C)OCc1ccc(CBr)cc1</smiles><smiles>CC(COc1ccc(F)cc1)OCc1ccc(CBr)cc1</smiles>

The decarboxylation was also observed when the reaction of I, II, and III was carried out at temperature higher than $150^{\circ} \mathrm{C}$. The product of such reaction (Table I, No. 10) did not exhibit absorption bands at $1740-1750 \mathrm{~cm}^{-1}$ in the IR spectrum. In the ${ }^{1} \mathrm{H}$ NMR spectrum of that product signals of methylene and methine protons neighboring with ether linkage were observed (Figure 3). These data indicate the formation of polyether according to eq 5 and 6. Similar decarboxylation reaction has been reported previously ${ }^{10}$ for the copolymerization of cyclic carbonates with cyclic anhydrides catalyzed by alkali metal salts. The studied reaction of I, II, and III run at high temperature, under carbon dioxide pressure was found to yield products containing carbonate linkages, which is evidenced by
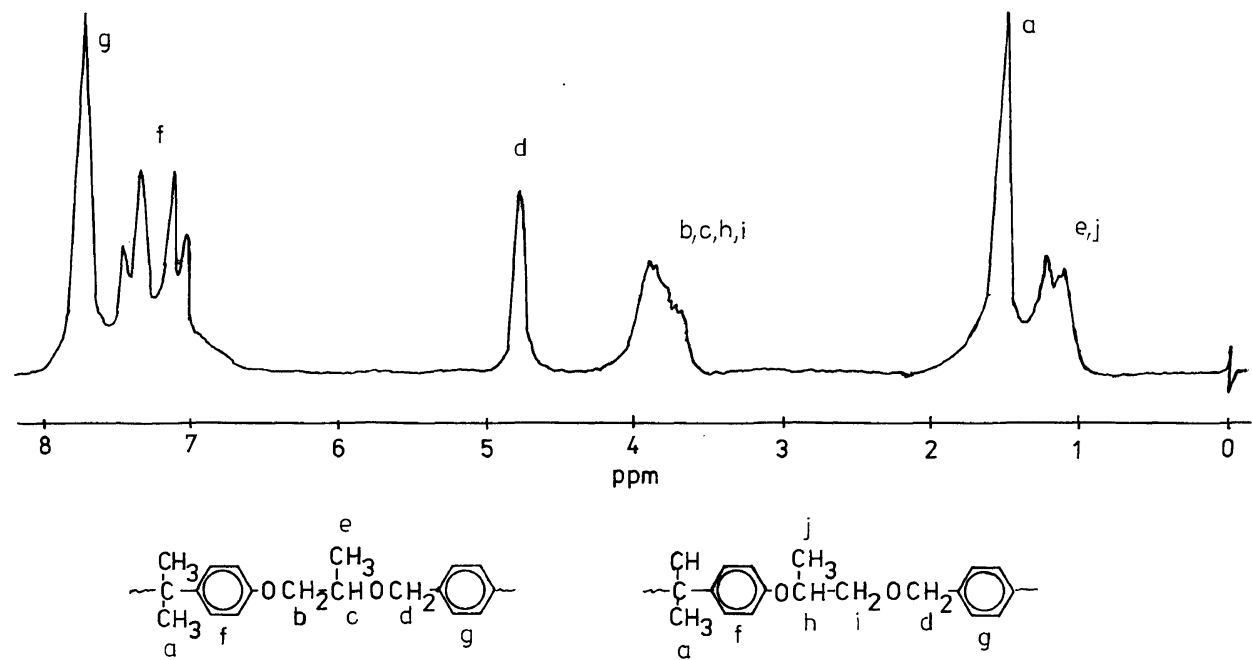

Figure 3. ${ }^{1} \mathrm{H}$ NMR spectrum of the product obtained from the reaction of dipotassium 4,4'-isopropylidenediphenolate, 4-methyl-1,3-dioxolan-2-one and $\alpha, \alpha^{\prime}$-dibromo- $p$-xylene (Table I, No. 10). 
${ }^{1} \mathrm{H}$ NMR and IR spectroscopic analyses (Table I, No. 11).

In order to confirm the mechanism of the reaction proceeding in the system I, II, and III the model reaction of 2-(1-phenoxy)propyl potassium carbonate with $\alpha, \alpha^{\prime}$-dibromo- $p$-xylene was carried out. The reaction of 2-(1-phen- oxy)propyl potassium carbonate (obtained from potassium 2-(1-phenoxy)propanolate (V) and carbon dioxide) with III was found to yield ether carbonate compound VII. The same compound VII was obtained from the reaction of potassium phenolate and 4-methyl1,3-dioxolan-2-one (scheme). It has been

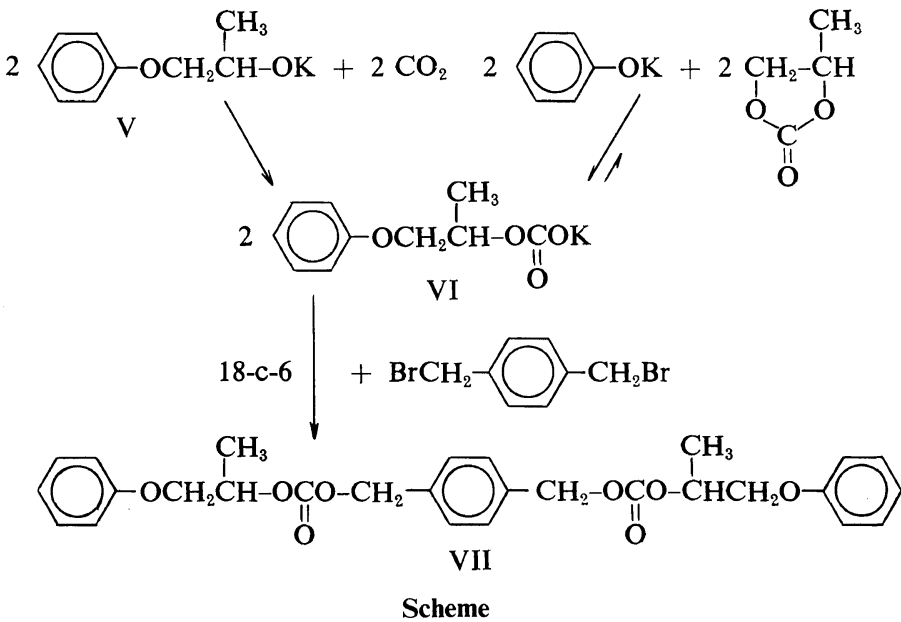

Table II. Reaction of dipotassium diphenolate (diolate), cyclic carbonate, and dibromo compound

\begin{tabular}{|c|c|c|c|c|c|c|c|c|c|c|c|c|}
\hline \multirow{3}{*}{$\begin{array}{c}\text { Run. } \\
\text { no. }\end{array}$} & \multirow{2}{*}{\multicolumn{2}{|c|}{$\begin{array}{l}\text { Diphenolate } \\
\text { (diolate) }\end{array}$}} & \multirow{2}{*}{\multicolumn{2}{|c|}{$\begin{array}{c}\text { Cyclic } \\
\text { carbonate }\end{array}$}} & \multirow{2}{*}{\multicolumn{2}{|c|}{$\begin{array}{l}\text { Dibromo } \\
\text { compound }\end{array}$}} & \multirow{3}{*}{ Solvent } & \multirow{3}{*}{$\frac{\text { Temp }}{{ }^{\circ} \mathrm{C}}$} & \multicolumn{2}{|c|}{ Reaction time } & \multirow{3}{*}{$\frac{\begin{array}{c}\text { Product } \\
\text { yield }\end{array}}{\mathrm{g}}$} & \multirow{3}{*}{$\frac{X_{\mathrm{c}}^{\mathrm{a}}}{\%}$} \\
\hline & & & & & & & & & I sten & II sten & & \\
\hline & \multicolumn{2}{|r|}{$\mathrm{g}(\mathrm{mmol})$} & & $\mathrm{g}(\mathrm{mmol})$ & & $\mathrm{g}(\mathrm{mmol})$ & & & $\min$ & $\mathrm{h}$ & & \\
\hline 1 & $\mathrm{IPP}^{\mathrm{b}}$ & $1.52(5)$ & $\mathrm{EC}^{\mathrm{c}}$ & $0.97(11)$ & $\mathrm{BBB}^{\mathrm{d}}$ & $1.32(5)$ & DMSO & 110 & 60 & 5 & 1.50 & 75 \\
\hline 2 & IPP & $1.52(5)$ & $\mathrm{StC}^{\mathrm{e}}$ & $1.80(11)$ & $\mathrm{BBB}$ & $1.32(5)$ & DMSO & 110 & 60 & 6 & 1.56 & 65 \\
\hline 3 & IPP & $1.55(5)$ & $\mathrm{AlC}^{\mathrm{f}}$ & $1.74(11)$ & BBB & $1.32(5)$ & DMSO & 110 & 60 & 5 & 1.47 & 72 \\
\hline 4 & IPP & $1.52(5)$ & $\mathrm{PC}^{\mathrm{g}}$ & $1.12(11)$ & $\mathrm{BBP}^{\mathrm{h}}$ & $1.70(5)$ & DMSO & 100 & 60 & 5 & 1.30 & 62 \\
\hline 5 & $S P^{i}$ & $1.63(5)$ & $\mathrm{PC}$ & $6.00(60)$ & $\mathrm{BBB}$ & $1.32(5)$ & - & 130 & 110 & 5 & 1.30 & 0 \\
\hline 6 & $\mathrm{CHD}^{\mathrm{j}}$ & $0.96(5)$ & $\mathrm{PC}$ & $1.12(11)$ & $\mathrm{BBB}$ & $1.32(5)$ & DOX & 40 & 60 & 6 & 1.05 & 45 \\
\hline 7 & $\mathrm{CHD}$ & $0.96(5)$ & $\mathrm{PC}$ & $6.00(60)$ & BBB & $1.32(5)$ & - & 60 & 60 & 6 & 1.60 & 78 \\
\hline 8 & CHD & $0.96(5)$ & $\mathrm{PC}$ & $1.12(11)$ & $\mathrm{BBB}$ & $1.32(5)$ & DOX & 110 & 40 & 5 & 1.71 & 80 \\
\hline
\end{tabular}

a $X_{\mathrm{c}}$, mole fraction of carbonate linkage.

b Dipotassium 4,4'-isopropylidenediphenolate (IPP).

c 1,3-Dioxolan-2-one (EC).

d $\alpha, \alpha^{\prime}$-Dibromo- $p$-xylene (BBB).

e 4-Phenyl-1,3-dioxolan-2-one ( $\mathrm{StC}$ ).

f 4-Allyloxymethyl-1,3-dioxolan-2-one (AlC).

g 4-Methyl-1,3-dioxolan-2-one (PC).

h 4,4'-Bis(bromomethyl)biphenyl (BBP).

' Dipotassium 4,4'-sulfonyldiphenolate (SP).

${ }^{j}$ Dipotassium 1,4-cyclohexanediolate (CHD). 
found that in the post-reaction mixture of VI (obtained from $\mathrm{V}$ and $\mathrm{CO}_{2}$ ) with dibromo compound small amount of 4-methyl-1,3-dioxolan-2-one, besides the main product VII, was present. This result shows the possibility of the "back-biting" type reaction followed by subsequent reaction of phenolate anion with dibromo compound leading to product with ether linkage.

The formation of cyclic carbonate is influenced by the presence of phenoxy group in VI. It seems interesting to mention that an analogous compound with alkoxy group instead of the phenoxy one does not form cyclic carbonate which was found for the reaction system consisting of diethylene glycol, $\mathrm{CO}_{2}$ and dibromo compound. ${ }^{11}$

It was found that by using various cyclic carbonates for the reaction with dipotassium diphenolate and dibromo compound one may obtain poly(ether-carbonate)s with various pendant groups (Table II, No. 2 and 3).

When dipotassium 1,4-cyclohexanediolate was applied for the reaction with 4-methyl-1,3dioxolan-2-one and $\alpha, \alpha^{\prime}$-dibromo-p-xylene corresponding poly(ether-carbonate) was formed at relatively low temperature in a high yield (Table II, No. 6-8).

\section{REFERENCES}

1. G. Rokicki, W. Kuran, and B. PogorzelskaMarciniak, Monatsh. Chem., 115, 205 (1984).

2. a) N. Yamazaki and S. Nakahama, Ind. Eng. Chem. Prod. Res. Dev., 18, 249 (1979); b) U.S. Patent 3896090 (1975), Chem. Abstr., 83, $164870 y$; U.S. Patent 4131731 (1978), Chem: Abstr., 87, 104 641j.

3. K. Soga, Y. Tazuke, S. Hosoda, and S. Ikeda, J. Polym. Sci., Polym. Chem. Ed., 15, 219 (1977).

4. a) K. Soga, Y. Toshida, S. Hosoda, and S. Ikeda, Makromol. Chem., 179, 2379 (1978); b) G. Rokicki, W. Kuran, and J. Kielkiewicz, J. Polym. Sci., Polym. Chem. Ed., 20, 967 (1982).

5. D. Kamm and C. S. Marvel, Org. Synth. Coll., 1, 29 (1941).

6. M. Tomita and K. Takahashi, J. Pharm. Soc. Jpn., 73, 760 (1953).

7. M. G. Voronkov and E. P. Popova, Latv. PSR Zinat. Akad. Vestis. Khim. Ser., 595 (1970); Chem. Abstr., 74, 42 034x (1971).

8. G. Gokel and D. Cram, J. Org. Chem., 39, 1070 (1974).

9. K. Soga, Y. Toshida, S. Hosoda, and S. Ikeda, Makromol. Chem., 178, 2747 (1977).

10. A. Hilt, J. Trivedi, and K. Hamann, Makromol. Chem., 89, 177 (1965).

11. G. Rokicki, unpublished data. 